\title{
When Rey-Osterrieth's Complex Figure Becomes a Church: Prevalence and Correlates of Graphic Confabulations in Dementia
}

\author{
Oriana Pelati $^{\mathrm{a}}$ Stefania Castiglioni ${ }^{\mathrm{a}}$ Valeria Isella ${ }^{\mathrm{b}}$ Marta Zuffi ${ }^{\mathrm{a}}$ \\ Francesca de Rino $^{a} \quad$ Ilaria Mossali $^{a}$ Massimo Franceschi ${ }^{a}$ \\ a Neurology Unit, IRCCS Multimedica, Castellanza, and b Neurology Section, Department of \\ Neurosciences, University of Milan Bicocca, Milan, Italy
}

\section{Key Words}

Dementia - Graphic confabulation • Rey-Osterrieth's complex figure $\cdot$ Verbal confabulation

\begin{abstract}
Verbal confabulation (VC) has been described in several pathological conditions characterized by amnesia and has been defined as 'statements that involve distortion of memories'. Here we describe another kind of confabulation (graphic confabulation, GC), evident at the recall of the Rey-Osterrieth complex figure (ROCF). In a retrospective study of 267 patients with mild-tomoderate dementia, 14 patients $(4.9 \%)$ recalled the abstract ROCF as drawings with recognizable semantic meaning. VC was evident at the story recall test in $19.8 \%$ of the study participants. VC and GC were homogeneously distributed among the different types of dementia. VC has been proposed to originate from complex interactions of amnesia, motivational deficit and dysfunction of monitoring systems. On the contrary, GC seems to be the result of a deficit in visual memory replaced by the semantic translation of isolated parts of the ROCF along with a source monitoring deficit.

Copyright $\odot 2011$ S. Karger AG, Basel
\end{abstract}

\section{Introduction}

The Rey-Osterrieth complex figure (ROCF) [1] is a widely used neuropsychological test that evaluates visuospatial and constructional abilities and organizational strategy in the copy stage and visual memory in the recall stage. Patients with visuoconstructional deficits produce distorted copies and impoverished drawings at recall. Amnesic patients copy the 
model adequately, but are only able to reproduce few or no element at recall. The trend of patients with frontal lobe dysfunction to perseverate or randomly distort the design is already evident in the copy and even more so in the recall stage [2].

Unlike these common errors, meaningful drawings (i.e. objects, animals or human figures) are rarely produced by patients at delayed recall of ROCF. Nevertheless, they are particularly intriguing if one considers that the original stimulus is a geometric and abstract figure intentionally not implying a semantic coding. The semantic content of these false memories, as well as the fact that patients are unaware that they are false, confers to them the features of 'graphic' confabulation (GC) [3].

Confabulation is a phenomenon occurring in amnesic patients due to a variety of brain disorders and has been puzzling clinicians since early ' 900 [4]. So far, there is no universally accepted definition for confabulations, but recently Metcalf et al. [3] defined them as 'statements or actions that involve distortions of memories' and explained them as a consequence of deficits of memory and executive control of retrieval. A traditional distinction is made between 'spontaneous' confabulations, when subjects produce untrue stories without apparent prompting, and 'provoked' confabulations, when subjects try to respond to direct questions probing faulty or imprecise memories [5]. According to this definition, confabulations at neuropsychological tests are to be considered as provoked confabulations. Rarely, spontaneous confabulations are reported and usually they are observed in verbal memory tasks such as story and word list recall (verbal confabulations, VC).

VC is considered as a typical sign of the Korsakoff's syndrome [6, 7], but it can also be observed in several other pathological conditions, such as aneurysm rupture in the Willis circle [8], brain injuries [9], dementia [10,11] and schizophrenia [12].

To the best of our knowledge, a formal report of such a kind of graphic production at visual memory tests or of any other GC or constructional confabulating behavior has not been published to date. The aim of this retrospective study was to explore the prevalence of $\mathrm{VC}$ at recall of a short story and of GC at the recall of ROCF in a large population of patients with cognitive deterioration, and to clarify their cognitive underpinnings through correlations with performance at usual neuropsychological tests.

\section{Patients and Methods}

\section{Patients}

We retrospectively considered clinical and neuropsychological data of all patients consecutively evaluated for suspect dementia at the Neurology Unit of the Multimedica Hospital, Castellanza, in 2005 and 2006. The diagnosis of dementia syndromes was based on clinical, neuropsychological, laboratory and neuroimaging data according to current research criteria for Alzheimer's disease (AD) [13], frontotemporal dementia (FTD) [14], vascular dementia $(\mathrm{VaD})[15]$ and mild cognitive impairment (MCI) [16].

\section{Neuropsychological Assessment}

All patients examined for story recall [17] and ROCF underwent a neuropsychological test battery examining the following cognitive domains: long-term verbal memory (Rey's 15-word list) [18], verbal and spatial short-term memory (digit span and Corsi span) [19], concentration skills (digit cancellation) [17], executive functions (Raven's colored progressive matrices) [20], language abilities (semantic verbal fluency [17], phonological verbal fluency [21] and token test [17]), visuospatial abilities (constructional apraxia [17]) and perceptual abilities (scrawl discrimination test [17]). The Mini-Mental State Examination (MMSE) [22] was used as a global measure of dementia severity. 

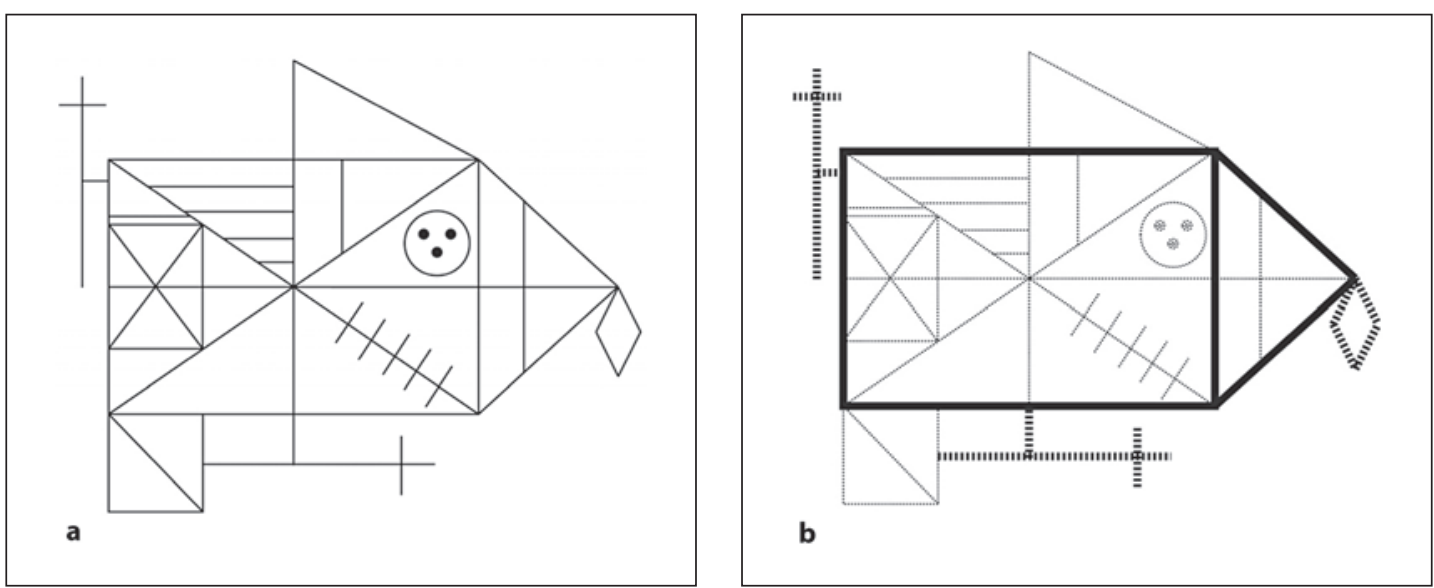

Fig. 1. a ROCF: original stimulus (Osterrieth, 1944). b In bold, the details of ROCF that would prompt the building and fish confabulation. c In bold, the detail of ROCF that would prompt the face and human figure confabulations.

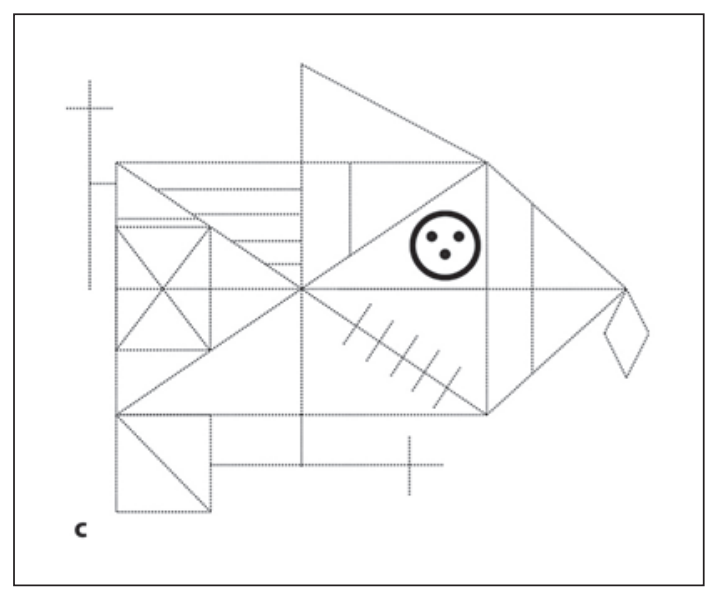

\section{Verbal Confabulation}

For the evaluation of VC there is no specific neuropsychological test though several questionnaires have been used [23]. We scored VC by applying to story recall the classification of errors described by Barigazzi et al. [24], which differentiates confabulations (elements unrelated to the original story or its main topic) from rationalizations (elements not present in the original story but coherent with its content) and logical-chronological errors (errors in the sequence or actors of events from the original story). VC was diagnosed when at least one confabulation was found in the story recall independently by the two expert neuropsychologists (O.P. and S.C.), as requested by Barigazzi et al. [24] criteria.

\section{Graphic Confabulations}

The patient is asked to copy the depicted ROCF (fig. 1a) as accurately as possible on the same sheet of paper, which cannot be rotated. After a 20 -min interval filled with verbal tasks, patients are asked to recall and draw the figure at their best. Patients are not previously informed that they will be asked to recall the figure, and are allowed as much time as they need for both copy and recall. For this study, we used the scoring method and normative data described by Carlesimo et al. [25].

We defined GC at recall as drawings unrelated to the target figure and with a recognizable semantic meaning. Two expert neuropsychologists (O.P. and S.C.), blinded to the diagnosis, reviewed ROCF of delayed reproductions; only when a consensus was reached, 
Table 1. Demographic data and MMSE scores of the study patients

\begin{tabular}{lllll}
\hline & $\mathrm{AD}(\mathrm{n}=113)$ & $\mathrm{FTD}(\mathrm{n}=76)$ & $\mathrm{VaD}(\mathrm{n}=36)$ & $\mathrm{MCI}(\mathrm{n}=42)$ \\
\hline Age, years & $75.2 \pm 6.2(59-88)$ & $72.3 \pm 7.3(52-85)$ & $74.3 \pm 6.9(58-84)$ & $73.7 \pm 7.7(51-87)$ \\
Males, \% & 35.4 & 43.4 & 50.0 & 38.1 \\
Education, years & $6.6 \pm 4.0(0-18)$ & $6.9 \pm 4.0(2-18)$ & $5.9 \pm 2.9(2-13)$ & $7.4 \pm 3.6(3-18)$ \\
MMSE raw score & $19.9 \pm 3.9(10-27)^{* * * *}$ & $20.9 \pm 4.7(4-30)^{*, * *}$ & $23.1 \pm 3.5(13-28)$ & $24.8 \pm 2.7(18-30)^{*}$ \\
\hline
\end{tabular}

${ }^{*} \mathrm{p}<0.05$ vs. MCI, ${ }^{* *} \mathrm{p}<0.05$ vs. VaD.

the drawing was classified as GC. Ambiguous drawings, i.e. drawings unrelated to the original stimulus but lacking a clear semantic meaning, or unrelated and meaningful elements incorporated in a complete or partial reproduction of the original stimulus, were excluded. Cases in which patients were aware of their failure in the recall were also not regarded as GC.

\section{Data Analysis}

Statistical analysis was performed with PASW Statistics 18.0 (SPSS, Chicago, Ill., USA). ANOVA or $\chi^{2}$ analysis was employed for group comparisons of sociodemographic and neuropsychological features of patients with different forms of dementia, as appropriate. Binary logistic regression was performed to predict confabulating behavior at story recall (confabulation: no/yes) or ROCF (confabulation: no/yes). Predictor variables included in the models were the interaction of diagnosis by MMSE score and neuropsychological measures tapping the main cognitive domains: word list delayed recall, digit span, attentional matrices, semantic and phonological fluency, token test, Raven's matrices and copy of ROCF. Scores at recall of the short story and of ROCF were excluded to avoid circularity.

\section{Results}

Of the 943 patients examined from 2005 to 2006, 471 met current diagnostic research criteria for either AD, FTD, VaD or MCI. The remaining 472 patients were not demented or affected by uncommon types of dementia, and therefore not considered for study entry. Two hundred and four patients were not administered the ROCF due to severity of dementia, sensory deficits or lack of cooperation. Of the 267 patients who performed the test, 113 (42.3\%) had AD, 76 (28.5\%) FTD, 36 (13.5\%) VaD and 42 (15.7\%) MCI.

Table 1 shows the main sociodemographic features and MMSE scores of the four groups: 67 patients (25.1\%) presented either or both types of confabulations - VC in 53 (19.8\%) and GC in 14 (5.2\%); 6 patients ( 3 AD and 3 FTD) presented with both VC and GC. Of the 53 patients with VC, 23 had AD (20.3\%), 19 FTD (25.0\%), $5 \mathrm{VaD}$ (13.9\%) and $6 \mathrm{MCI}(14.3 \%)$, with no intergroup statistically significant difference in prevalence. Of the 14 patients with GC, 7 had AD (6.2\%), 4 FTD (5.3\%) and $3 \mathrm{VaD}$ (8.3\%), while GC were absent in MCI patients. Again, there was no between- and within-group statistical significance.

Figure 2 displays GC productions. In the AD group, 5 patients recalled the ROCF as a church or a house, 1 patient drew a face and another patient a whole human silhouette. In the FTD group, 2 patients drew a house, 1 patient a house surrounded by a garden with a woman inside (verbally accounted as herself) and 1 patient drew a fish. Among VaD patients, 2 patients drew a house and 1 a flower pot. 


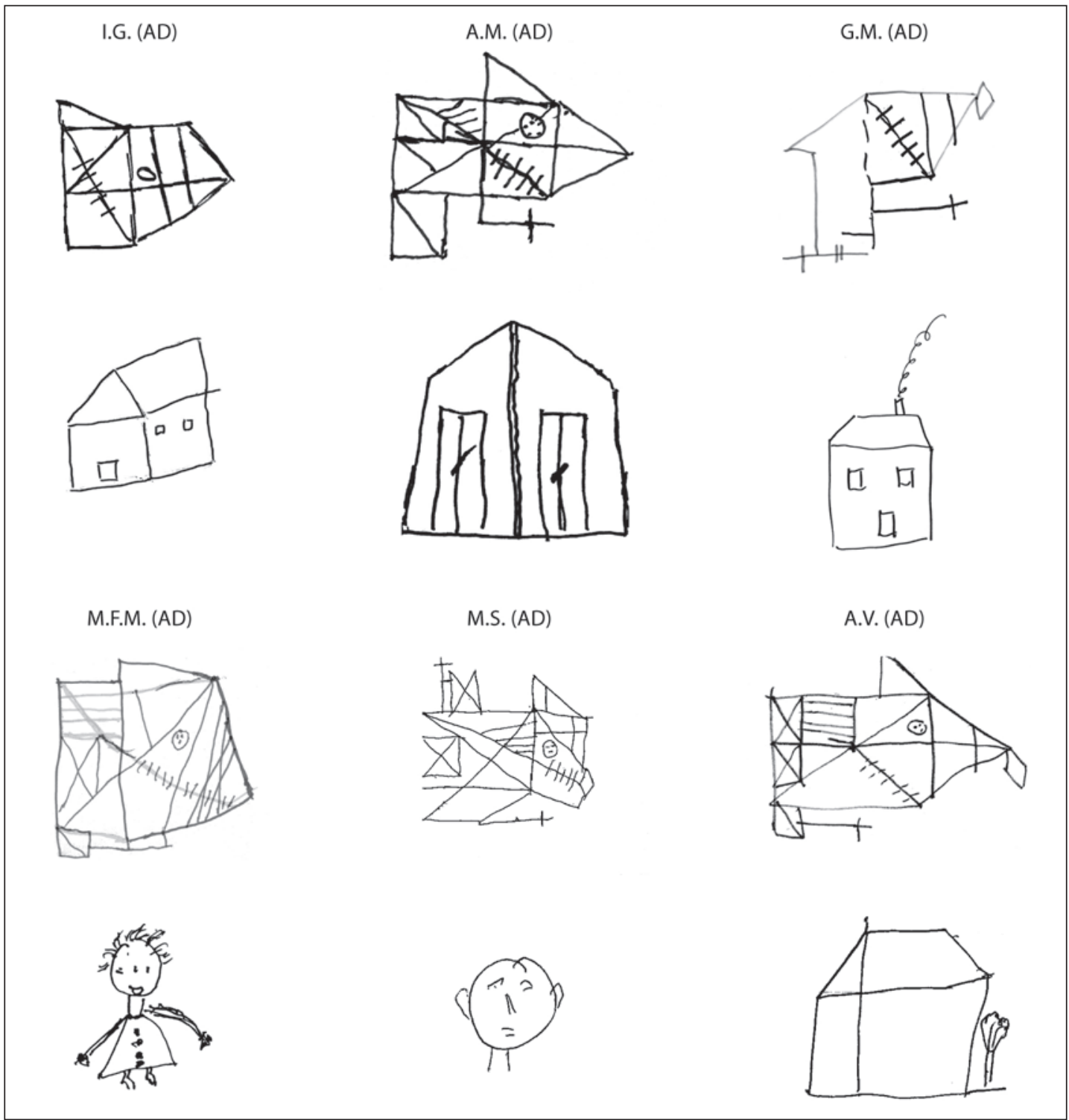

Fig. 2. Copy (above) and recall (below) of ROCF in confabulating patients.

The model derived from logistic regression conducted to predict confabulating behavior at story recall showed only a trend towards significance $\left(\chi^{2}=3.309, \mathrm{p}=0.069\right.$, d.f. $\left.=1\right)$. Nagelkerke's $\mathrm{R}^{2}$ indicated that the model explained $2.3 \%$ of the variance. The percentage of subjects correctly classified was $81.1 \%$. The only variable that approached significance as a predictor of VC was word list delayed recall $[\mathrm{B}=-0.174, \mathrm{SE} \mathrm{B}=0.104$, Wald $=2.799$, d.f. $=1$, $\mathrm{p}=0.094, \operatorname{Exp}(\mathrm{B})=0.840,95 \%$ confidence interval 0.685-1.030).

Logistic regression analysis conducted to predict GC yielded a statistically significant model $\left(\chi^{2}=9.921, \mathrm{p}<0.05\right.$, d.f. $\left.=4\right)$. Nagelkerke's $\mathrm{R}^{2}$ indicated that the model explained $11.5 \%$ of the variance. The percentage of subjects correctly classified was $93.9 \%$. The only variable that made a significant contribution to prediction was the semantic fluency score $[\mathrm{B}=-0.179, \mathrm{SE} \mathrm{B}=0.085$, Wald $=4.388$, d.f. $=1, \mathrm{p}=0.036, \operatorname{Exp}(\mathrm{B})=0.836,95 \%$ confidence interval $0.708-0.989$ ]: the odds of a patient to produce GC are increased by a factor of 0.8 for a unit decrease in the semantic fluency score. 
$E_{X} X R_{1}$

Dementia

and Geriatric

Cognitive Disorders
Dement Geriatr Cogn Disord Extra 2011;1:372-380

DOI: 10.1159/000332019

Published online: November 5, 2011

(c) 2011 S. Karger AG, Basel

www.karger.com/dee

Pelati et al.: Confabulations in Dementia
M.Z. (AD)
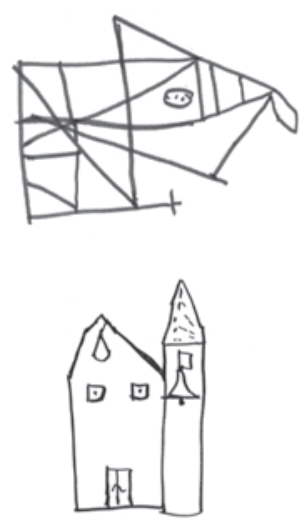

C.P. (FTD)
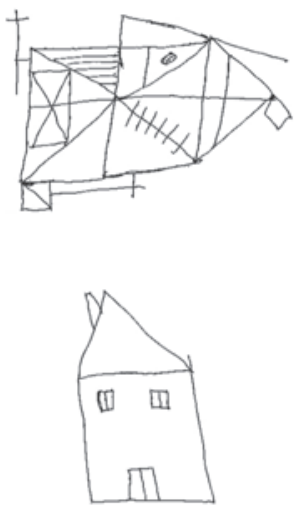

P.B. (VaD)
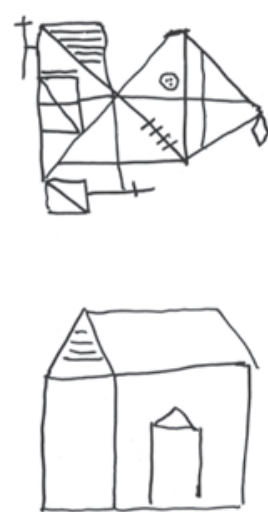

M.B.B. (FTD)
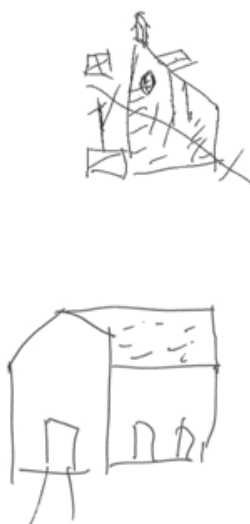

R.S. (FTD)
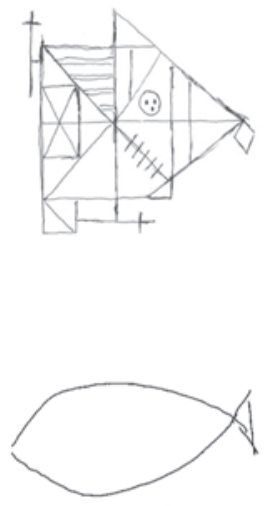

S.M. (VaD)
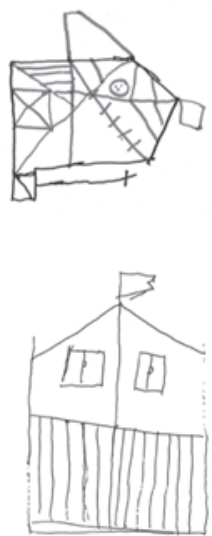

A.D. (FTD)
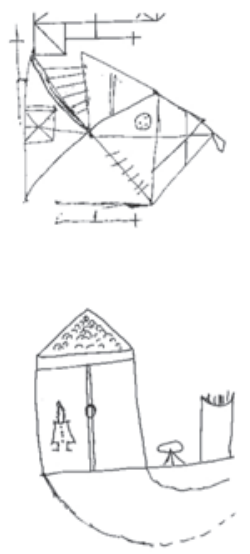

M.B. (VaD)
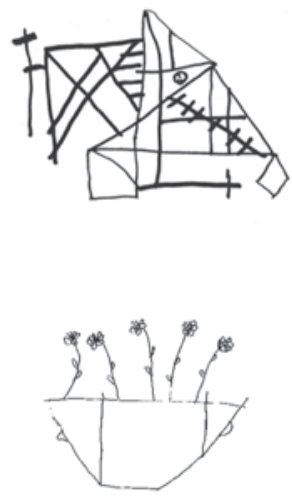

Fig. 2 (continued) 


\section{Discussion}

In a retrospective evaluation of a large population of demented patients, we identified a form of confabulation, i.e. 'actions that involve distortions of memories', evident at the recall of the ROCF and never described before. This form of GC passed unobserved up to now due to its limited ecological impact, but it could be interesting for the interpretation of the more studied and known VC.

In a large population of patients with dementia or MCI, total prevalence of GC was approximately $5 \%$ and uniformly distributed in the three main types of dementia (AD, FTD and $\mathrm{VaD})$.

To the best of our knowledge, data on the prevalence of VC in dementia are lacking. In our population, VC was relatively frequent (19.8\%), and less common in VaD and MCI, but without any clear correlation with age, gender, severity of dementia or specific cognitive deficits. VC was uniformly present in men and women, while 13 of 14 patients with GC were women.

The cognitive profiles of confabulating and non-confabulating patients were similar, and only GC could be predicted by poor performance on semantic fluency.

One previous study [11] directly compared a selected sample of AD and FTD patients and found a higher incidence of VC in FTD patients. In our sample, we did not replicate this finding, neither for $\mathrm{VC}$ nor for GC, which were equally frequent among the two diseases. In contrast to the study by Nedjam et al. [11], our patients were not matched for sociodemographic variables and disease severity, and this might account for the discrepancy. Moreover, they used a VC-specific questionnaire while in our retrospective study we investigated VC using the story recall test.

Finally, the size of the two samples were significantly different: 22/10 AD/FTD in the series of Nedjam et al. [11] compared to 117/77 AD/FTD in our series.

The main theories of confabulation generally highlight the importance of deficits in frontal-executive functions and in the memory domain for the development of confabulations. Metcalf et al. [3] have recently proposed a new model of spontaneous confabulations based on Langdon and Coltheart's [26] cognitive model of delusional belief information. According to this theory, failures in the executive control of retrieval and plausibility judgment, along with disorganization of autobiographical memory, and individual emotional and motivational biases, all contribute to generate a spontaneous confabulation. While some degree of memory impairment seems to be essential $[5,27]$, frontal dysfunction appears to be frequent $[4,28]$ but perhaps not necessary and certainly not sufficient $[5,11]$, at least as far as a general deficit in executive control on retrieval or response monitoring are concerned. Recently, a more specific frontal deficit causing confabulating retrieval has been proposed, operating in conjunction with memory impairment [29]. Paralleling behavioral observations, neuroimaging of lesions in confabulating patients also suggests the involvement of multiple systems, the ventromedial prefrontal cortex [28-30] as well as more posterior cortical areas, in memory processes [31]. Our findings on GC are generally in agreement with those reported in the literature on $\mathrm{VC}$, pointing to a dysexecutive-amnesic involvement. However, the relative weight of the frontal and memory deficits in determining GC seems to be variable in different cognitive syndromes. Previous evidence on VC in AD $[11,32]$ indicates that they are related to memory impairment rather than to frontal dysfunction, while a recent paper [31] reported that episodic confabulation is affected by delusion related to frontal dysfunction, and semantic confabulation is more closely associated with memory disorder. In our sample, GC is limited to demented patients, while VC also presented in MCI patients, suggesting that in this form of confabulation memory deficits are critical, with the dysexecutive component being less important. 
Most of the GC we observed (10 of 14) were drawings of buildings (a house or a church). By comparing them with the original ROCF, we hypothesize that they may derive from a semantic reprocessing of details referred to as Nos. 2 and 13 in the classification of ROCF elements of Carlesimo et al. [25] (fig. 1b). The drawings of the fish and the flower pot likely relate to these same details, though more loosely. The face and the human figure might instead have been inspired by detail No. 11 (fig. 1c). These observations imply that GC might primarily be prompted by automatic semantic processing of ROCF during copying. Guerin et al. [33] reported that visuoperceptive analysis of the stimulus cooperates with some semantic activation provided by visual imagery in patients copying meaningless drawings. Accordingly, we may hypothesize that two different processes are ongoing during the copy of Rey's figure: analysis and incidental learning of perceptive schemata and automatic retrieval of semantic representations. Attali et al. [32] recently demonstrated that overlearned information of a semantic nature is involved in confabulations. In our study, we confirmed that activated semantic memories may replace memory for meaningless graphic elements in amnesic patients, or in patients with a dysfunction of the retrieval monitoring system.

Our study certainly has limitations, mainly due to its retrospective design. However, we feel to have raised some interesting issues about a new kind of confabulation, we are planning to address in a future prospective study. In the future, it will be necessary to prospectively evaluate VC by one of the several questionnaires available. Moreover, it will be useful to administer patients with GC at ROCF a different graphic source (the Taylor design, for example) to test whether or not GC is specifically related to the target. GC in dementia represents a phenomenon so far neglected, but potentially useful to explain cognitive mechanisms of confabulation in general, and the intimate relationships between memory mechanisms and their executive control.

\section{References}

1 Osterrieth PA: Le test de copie d'une figure complexe. Arch Psychol 1944;30:206-356.

2 Lezak MD: Neuropsychological Assessment, ed 3. Oxford, Oxford University Press, 1995, pp 475480.

-3 Metcalf K, Langdon R, Coltheart M: Models of confabulation: a critical review and a new framework. Cogn Neuropsychol 2007;24:23-47.

4 Bonhoeffer K (cited in Talland, 1961): Der Korsakowsche Symptomenkomplex in seinen Beziehungen zu den verschieden Krankheitsformen. Allg Z Psychiatr Psych Med 1904;61:744-752.

-5 Kopelman MD: Amnesia: organic and psychogenic. Br J Psychiatry 1987;150:428-442.

-6 Talland GA: Confabulation in the Wernicke-Korsakoff syndrome. J Nerv Ment Dis 1961;132:361381.

7 Dalla Barba G, Cipollotti L, Denes G: Autobiographical memory loss and confabulation in Korsakoff's syndrome: a case report. Cortex 1990;26:525-534.

8 Deluca J, Diamond B: Aneurysm of the anterior communicating artery: a review of neuroanatomical and neuropsychological sequelae. J Clin Exp Neuropsychol 1995;17:100-121.

$\checkmark 9$ Dalla Barba G: Different patterns of confabulation. Cortex 1993;29:567-581.

-10 Green J, Hodges JR, Baddeley AD: Autobiographical memory and executive function in early dementia of Alzheimer type. Neuropsychologia 1995;33:1647-1670.

-11 Nedjam Z, Devouche E, Dalla Barba G: Confabulation, but not executive dysfunction discriminate AD from frontotemporal dementia. Eur J Neurol 2004;11:728-733.

-12 Kopelman MD, Guinan EM, Lewis PDR: Delusional memory, confabulation and frontal lobe dysfunction: a case study in De Clerambault's syndrome. Neurocase 1994;1:71-77.

-13 McKhann G, Drachman D, Folstein M, et al: Clinical diagnosis of Alzheimer's disease: report of the NINCDS/ADRDA Work Group under the auspices of Department of Health and Human Services Task Force on Alzheimer's disease. Neurology 1984;34:939-944. 
14 Neary D, Snowden JS, Gustafson L, et al: Frontotemporal lobar degeneration: a consensus on clinical diagnostic criteria. Neurology 1998;51:1546-1554.

-15 Roman GC, Sachdev P, Royall DR, et al: Vascular cognitive disorder: a new diagnostic category updating vascular cognitive impairment and vascular dementia. J Neurol Sci 2004;226:81-87.

-16 Petersen RC: Mild cognitive impairment as a diagnostic entity. J Intern Med 2004;256:183-194.

17 Spinnler H, Tognoni G: Standardizzazione e taratura italiana di test neuropsicologici. It J Neurol Sci 1987, suppl 8.

18 Carlesimo GA, Caltagirone C, Gainotti G, et al: Batteria per la valutazione del deterioramento mentale (Parte II): standardizzazione e affidabilità diagnostica nell'identificazione di pazienti affetti da sindrome demenziale. Arch Psicol Neurol Psichiatr 1995;4:461-470.

-19 Orsini A, Grossi D, Capitani E, et al: Verbal and spatial immediate memory span: normative data from 1355 adults and 1112 children. It J Neurol Sci 1987;8:539-548.

-20 Basso A, Capitani E, Laiacona M: Raven's coloured progressive matrices: normative values on 305 adult normal controls. Funct Neurol 1987;2:189-194.

21 Novelli G, Papagno C, Capitani E, et al: Tre test clinici di memoria verbale a lungo termine. Taratura su soggetti normali. Arch Psicol Neurol Psichiatr 1986:47:278-296.

-22 Magni E, Binetti G, Cappa S, et al: Effect of age and education on performance on the Mini Mental State Examination in a healthy older population and during the course of Alzheimer's disease. J Am Geriatr Soc 1995;43:942-943.

23 Dalla Barba G: Confabulation: knowledge and recollective experience. Cogn Neuropsychol 1993;10: $1-20$.

24 Barigazzi R, Della Sala S, Laiacona M, et al: Esplorazione testistica della memoria di prosa. Ric Psicol 1987;1:49-80.

25 Carlesimo GA, Buccione I, Fadda L, et al: Standardizzazione italiana di due test di memoria per uso clinico: breve racconto e figura di Rey. Riv Neurol 2002;12:1-13.

26 Langdon R, Coltheart M: The cognitive neuropsychology of delusions; in Coltheart M, Davies M (eds): Pathologies of Belief. Oxford, Blackwell, 2000, pp 183-216.

-27 Dalla Barba G, Cappelletti JY, Signorini M, Denes G: Confabulation: remembering 'another' past, planning 'another' future. Neurocase 1997;3:425-436.

-28 Fischer RS, Alexander MP, D'Esposito M, Otto R: Neuropsychological and neuroanatomical correlates of confabulation. J Clin Exp Neuropsychol 1995;1:20-28.

-29 Turner MS, Cipolotti L, Yousry TA, Shallice T: Confabulation: damage to a specific inferior medial prefrontal system. Cortex 2008;44:637-648.

30 Gilboa A, Moschovitch M: The cognitive neuroscience of confabulation: a review and a model; in Baddley A, Kopelman MD, Wilson B (eds): The Handbook of Memory Disorders. Chichester, Wiley, 2002, pp 315-340.

-31 Lee E, Kinomura S, Meguro K, et al: Confabulations on episodic and semantic memory questions are associated with different neurologic backgrounds in Alzheimer disease. Cogn Behav Neurol 2009; 22:81-88.

32 Attali E, De Anna F, Dubois B, Dalla Barba G: Confabulation in Alzheimer's disease: poor encoding and retrieval of overlearned information. Brain 2009;212:132-204.

-33 Guerin F, Ska B, Belleville S: Cognitive processing of drawing abilities. Brain Cogn 1999;40:464-478. 